\title{
Acquisition of Microfilms: Commercial and Institutional Sources'
}

$\mathrm{P}$ URCHASING activities in connection with the acquisition of microfilm in scholarly libraries tend to fall into two classes. The first class is comparable to normal book purchasing activity ; that is, filming agencies, either private filming concerns or institutional libraries, engage in the business of selling positive film prints from their master negatives. These agencies may offer to sell positive film copies of individual books, newspapers, periodicals, and manuscripts at a fixed price per title, or they may require subscription to an entire filming project, involving many titles or manuscripts, at an annual subscription cost or at a fixed subscription rate for the entire series. Orders for positive film prints are usually entered directly with the filming agency concerned. By way of illustration, some examples of filming agencies selling positive microfilm prints may be given.

The firm of Southwestern Microfilms, Inc., of Dallas, Tex., has filmed a number of books in the field of early Western Americana, its selection to some extent being based on Wagner's bibliography of the Plains and the Rockies. Individual titles may be purchased at a fixed price, and catalogs listing the titles for the series are issued periodically. Since many of the titles included in Southwestern lists are not likely to be obtainable in original book form or except at high prices, the college or university library may wish to use these

${ }^{1}$ Paper given before the Conference of College and University Librarians, at University of Southern California on Nov. 17, I 945 . catalogs as a buying guide to materials needed in their collections.

Another commercial filming agency is that of University Microfilms, of Ann Arbor, Mich., directed by Eugene B. Power. Mr. Power, foreseeing the full commercial possibilities of microphotography, has pioneered in this field, to which he has made several contributions. It is due to his enterprise that there was begun several years ago the filming of all books before 1600 listed in Pollard and Redgrave's ShortTitle Catalogue of ... English Books. This project is sold to subscribing libraries at a flat rate of $\$ 500$ per year, for which sum film of one hundred thousand pages per year is supplied. It is roughly estimated that the project will require some thirteen years to complete. Titles which have been filmed to date for the project are indicated in W. W. Bishop's Checklist of American Copies of "Short-Title Catalogue" Books, published in 1944. One might suppose it possible to purchase positive film prints of single titles from the negatives on file in this series, but, for the present, orders for positive films of individual titles are diffcult to obtain, as the profit for the filming agency lies in the subscriptions for the entire series; and, practically, until the contents of the numerous reels of negatives are fully cataloged, it is not profitable for them to take the time necessary to locate single scattered titles on the many reels of film.

A second project of University Microfilms is that of filming American periodicals 
prior to I 825, which is also sold on a subscription basis of $\$ 450$ per year per 100,000 pages, including one set of catalog cards for each title filmed. Closely related to the American periodical project is the American Culture series, consisting of films of texts of the original editions of approximately 250 books of representative writings about America and Americans published between I 493 and I800. This series is also sold on a subscription basis.

Still another project carried out by this firm is one in which microphotography has been used as a publishing medium. This is the University Microfilms' program of filming doctoral dissertations. The publication Microfilm Abstracts calls attention to all dissertations so filmed and quotes the cost of positive film copies or paper enlargements.

Many other projects of commercial firms could be noted, but attention may now be given to projects instituted by societies in cooperation with libraries and by libraries themselves. The Modern Language Association of recent years has largely turned its program of securing photostat reproductions of books and manuscripts in its field of study to a microfilming program. Microfilms selected and acquired by the Modern Language Association are deposited in the Library of Congress, and the photoduplication service of the Library of Congress can supply positive microfilm prints of these materials. In 1942 the Modern Language Association issued a pamphlet listing the materials photographed in the series, and P.M.L.A. has included at least one supplementary list since then. Arrangements also exist whereby libraries contributing annually to the Modern Language Association filming project receive, as a bonus, two thousand frames of microfilms per year, chosen from the materials copied.

During the war the Committee on $\mathrm{Mi}$ - crocopying Materials for Research of the American Council of Learned Societies began, as a wartime measure, the filming of materials in England endangered by military action. Carefully selected lists of research materials in a wide variety of fields were prepared as a guide in this film undertaking. The Library of Congress serves as a depository for the completed film negatives and can supply positive film duplications at small cost.

The National Archives have instituted a microfilm series known as the "File Microcopy" program. It is their intention to make master microfilm negatives of their significant holdings, from which positive film prints can be furnished at a nominal cost. Brown University has two important filming projects; one, the Mathematical Reviews series and the other, Latin Americana before 1800 , for both of which positive film copies can be furnished. The $\mathrm{Li}^{-}$ brary of Congress in cooperation with the University of North Carolina has filmed an impressive number of state legislative journals, obtainable in positive film prints.

\section{Filming Newspapers}

Finally, numerous old and current newspapers are obtainable in positive microfilm copies made from master negatives, which are variously owned by the publisher of the newspaper, independent filming agencies, or some sponsoring library. Projects of filming older files have frequently been sponsored by libraries, as, for example, the film reproduction of the Maryland Gazette, I 745-1 820 , by Yale University Library, and the Pennsylvania Gazette, I 728-1 879, by the Historical Society of Pennsylvania. The newspaper publisher himself may also undertake the filming of the back files and current issues of his own paper and sell positive film copies to consumers.

It seems appropriate at this point, in a 
discussion of the purchase of positive film copies reproduced from master negatives, to point out that there is no coordinated medium of making known to libraries the various filming projects undertaken by private and institutional filming agencies, so that the order librarian must be constantly on the lookout for such information. References to reproductions that have actually been made or are in progress have been scattered through library periodicals, committee reports, and the literature of other fields, and some searching is required to track them down. For the brief period of five years, from 1938-42, the Journal of Documentary Reproduction was published under the editorial supervision of the American Library Association's Committee on Photographic Reproduction of Library Materials. This quarterly publication, besides dealing with the technical aspects of the subject, contained notices of filming projects and included bibliographies of newspapers available on film to which supplements appeared from time to time. A file of this publication is still useful to the order librarian seeking information on materials for which master negatives exist. It is heartening to learn from a recent report of the American Library Association committee that it is its intention to revive this periodical at the earliest opportunity and to publish volumes for the interim years.

\section{Union List of Microfilms}

Still another effort has been made to locate, in convenient form, microfilm materials in this country. The Philadelphia Bibliographical Center issued in 1942 the Union List of Microfilms, which included 522 I titles. Annual supplements for 1942, 1943, and 1944, totaling another 954 I titles, have also been issued. Though a complete response from libraries was not forthcoming, over one hundred institutions have reported their holdings to the center and, in addition, titles of books and newspapers filmed by commercial agencies have been included. The value of such a union list to the order librarian would lie in the knowledge that the institution owning the negative could supply a positive film copy on request. Actually, many owning libraries do not possess equipment to make positive film prints, but, even granting they could be supplied, the question of the quality of the negative from which they are to be made has to be taken into consideration, as negatives vary greatly and many are not worthy of duplication. The next few years will probably bring about a higher quality of microfilming and, as microfilming facilities are more widely developed in this country, it will be possible for librarians to order positive film prints from such negatives.

\section{Cumulative List Needed}

Apropos of this whole subject of making known the existence of master film negatives, Herman H. Fussler, of the University of Chicago Libraries' Department of Photographic Reproduction, has suggested the need for a cumulative publication for microfilm reproductions similar to the Wilson series of cumulative indexes for books, so that libraries can keep informed of materials reproduced through this photographic technique and, if desired, acquire positive film prints from the filming agency.

The foregoing discussion of film acquisitions has been concerned with acquiring positive film copies made from master negatives owned by some filming agency which sells positive film duplications. The second class concerns itself with the acquisition of negative film reproductions made directly from original materials. This class of microfilm acquisitions requires a different approach than the first ${ }^{-}$class and combines with it some of the features of interlibrary 
loan work, in that the order librarian will benefit by a knowledge of those library tools which locate research materials in various libraries at home and abroad, since the first step in ordering microfilm negatives is to locate original copies. After he has located the original copies, the order librarian uses his knowledge of the quality of film work produced by the photographic departments or the filming agents of the institutions owning copies as well as the relative charges for their copying services, since differences in quality and cost may be great and should be taken into consideration.

For this class of microfilm orders the order librarian will also find it necessary to familiarize himself with some of the more technical aspects of microphotography. He will wish to have a firsthand knowledge of the film reading machines owned by his library, so that he can order film to the specifications best suited for them. He will also wish to understand something of reduction ratios, that is, whether, judging from the size of the original, it is more desirable to film the book one or two pages to a frame or exposure. This latter knowledge is of importance also in determining in advance the probable cost of microfilming a book, newspaper, or manuscript, as the order librarian in the process of locating copies of the original has at the same time endeavored to ascertain the size of the original and its pagination. Most filming agencies will supply quotations on request, but, if time is of the essence, much delay can be avoided by being able to calculate the probable cost. The quality and type of the film itself is another variable factor and, to insure a high quality of film being supplied, it is well to be informed on the acceptable standards in microfilm. Finally, the question may arise as to whether or not the material being requested on film is required for study purposes only and deposit in the library's collections, or if it is desired for publication in whole or in part, since some libraries wish to control the use made of their rare books and manuscripts. For these latter institutions it will save time if the order carries with it a statement of the purposes for which the film copy is required.

For this class of orders the order librarian has at his service a helpful Directory of Microfilm Sources, compiled by Ross C. Cibella and published by the Special Libraries Association in 1941. This volume is already out of date and not completely adequate to the situation but it is soon to be issued in a revised edition. The directory lists libraries in the United States, Canada, and England having microfilming services, as well as commercial concerns, and includes facsimiles of the order forms of some of the larger filming organizations. These order forms carry much useful information and a file of them collected from major filming sources is useful to the order librarian. Notices of the establishment of new microfilming services are making their appearance more or less regularly now in our professional periodicals.

\section{Filming Laboratories}

The United States is fortunate in that most of the major research collections in the country have either their own filming laboratories or have arrangements whereby an outside filming agency can do the work. The Library of Congress has an outstanding photoduplication service and not only films material owned by the national library but will film materials from neighboring libraries, as, for instance, the Folger Shakespeare Library. The National Archives is equipped to supply film copies of its materials. Bibliofilm Service, located in the library of the U.S. Department of Agriculture, can supply film copies of materials in the libraries of the Department of Agricul- 
ture, the Geological Survey, and the National Bureau of Standards. The Army Medical Library operates its own medicofilm service. In New York, the New York Public Library has an extensive microfilm service, as does Columbia University Libraries, which also films books in the library of the Union Theological Seminary. Most of the major university libraries in the country have filming laboratories, among them Harvard, Brown, Yale, Illinois, Minnesota, Princeton, $\mathbf{W}$ isconsin, Virginia, Texas, the University of California at Berkeley, and the University of Chicago, whose finely equipped laboratory is also the filn reproductive agency for the following libraries in the Chicago area: Newberry, John Crerar, Chicago Public, and Chicago Theological Seminary. Microfilm copies of materials in the University of Michigan Libraries are supplied by University Microfilms. In California, besides the laboratory of the University of California at Berkeley, the Huntington Library has for some years supplied film copies of materials in its collections, and it is understood that the California State Library and the Los Angeles Public Library have planned facilities.

Ordering microfilms of research materials from English libraries has been greatly facilitated by the service offered by University Microfilms. This firm has cameras in the British Museum, Bodleian Library, Cambridge University Library, and the Public Records Office, and can also obtain microfilm from some of the smaller outlying libraries in that country. All film orders to the British Museum and the Bodleian Library can be placed directly with University Microfilms, but for other English libraries, requests for microfilm should be placed directly with their respective librarians. In passing it might be said that, in general, English librarians are loath to accept "orders" for microfilms, though they are glad to consider "requests" for them. As a group they are more likely to be concerned with the use to be made of materials filmed and frequently require a written statement of the purpose for which film copies are desired. The British Museum is an exception to the foregoing, except where publication privileges of unique materials are involved.

On the Continent, University Microfilms has a camera in the Bibliothèque Nationale in France, at the Vatican in Rome, and in Amsterdam this firm has an agent to execute film commissions. Orders for materials in the Bibliothèque Nationale can be placed directly with University Microfilms. Commenting in general on his microfilming services abroad, Mr. Power writes:

The result is that, at least in those countries where cameras are located, microfilm copies of books and manuscripts may be obtained without great difficulty. You realize, of course, that there are always some restrictions on the copying of materials of this sort. The charge varies somewhat, depending upon the location of the original and the amount to be done. In general, however, in no instance is the cost more than that charged by the library itself, if the order is placed directly.

In conclusion, brief mention may be made of one other procedure of film acquisition by a library having its own microfilming facilities. This is to borrow the originals for filming in its own laboratory, providing the owner is willing to lend them for this purpose. It can have one great advantage so far as the cataloger is concerned, in that if the period of loan is sufficient it enables him to catalog from the original rather than the film copy. The Huntington Library has found this method highly satisfactory and has so cataloged and filmed a large number of pamphlets dealing with the English Civil War, owned by the Sutro Branch of the California State Library, which lacked its own filming facilities. 